* Professor titular dos Cursos de Doutorado, Mestrado e Graduação em Ciência Jurídica na Universidade do Vale do Itajaí. Graduado em Direito pela Universidade do Vale do Itajaí (2002), graduação em Ciências da Computação pela Universidade Federal de Santa Catarina (1984), mestrado em Engenharia de Produção pela Universidade Federal de Santa Catarina (1992), mestrado em Ciência Jurídica pela Universidade do Vale do Itajaí (2005) e doutorado em Engenharia de Produção pela Universidade Federal de Santa Catarina (2000). Email: alvaro@univali.br

** Mestrando em Ciências Jurídicas pela Universidade do Vale do Itajaí. Bacharel em Direito pela Universidade de Passo Fundo. E-mail: felipe.itajai@schulze.com.br

\section{Soberania nacional e privatização dos terminais portuários}

\section{NATIONAL SOVEREIGNTY AND PRIVATIZATION OF PORT TERMINALS}

\author{
Alvaro Borges de Oliveira * \\ Felipe André Dani **
}

Resumo: Inicia-se o presente artigo fazendo referência a soberania Estatal. Na seqüência abordam-se a questão dos portos públicos e dos portos privados, dando ênfase aos portos privados da Grã-Bretanha e da China. Ao final, faz-se referência as agências reguladoras, dando enfoque especial a Agência Nacional dos Transportes Aquaviários - ANTAQ, e sua importância na regulação/fiscalização das instalações portuárias.

Palavras-Chave: Soberania; Portos; Agências Reguladoras; ANTAQ.

Abstract: The present article is initiated making reference the State sovereignty. In the sequence they approach it question of the public ports and the private ports, giving emphasis to the private ports of Great-Britain and China. To the end, reference becomes the regulating agencies, giving to special approach the National Agency of the Transports - ANTAQ, and its importance in the regulation/fiscalization of the port installations.

Keywords: Sovereignty. Ports. Regulating Agencies. ANTAQ. 


\section{INTRODUÇÃO}

A soberania é um elemento intrínseco dos Estados, um poder de organizar-se, auto gerindo-se e comandando-se, sempre preocupado com o bem comum.

O Estado Democrático de Direito traz a soberania como fundamento, porém ele é também justificador para a limitação do estado soberano, impondo limites necessários para a soberania não sufocar sujeitos e instituições.

A soberania permite a regulação, a criação de normas reguladoras que conseqüentemente diminuem a discricionariedade dos operadores portuários particulares, permite assim, a criação de um direito regulatório para regular portos privados.

A economia e princípios capitalistas influenciaram na crítica a eficiência de alguns Estados na prestação de serviços, e no atendimento das necessidades e anseios sociais relativos ao transporte marítimo e as atividades portuárias.

Os portos também são atingidos por princípios de eficiência e rentabilidade e a grande maioria não possui instalações adequadas, principalmente mão-de-obra qualificada e tecnologia para atender as demandas de seus utilizadores.

A privatização dos portos ocorreu, por exemplo, na Grã-Bretanha, onde os portos foram utilizados pela iniciativa privada como forma de investimento inicialmente, e após melhorias e investimentos, foram agregados eficiência e rentabilidade aos seus utilizadores. Outro exemplo de portos privados ocorre na China, que devido a crescimentos econômicos brilhantes tinha nos portos um gargalo logístico para escoamento de toda a sua produção, sendo assim a privatização dos portos trouxe maior eficiência no escoamento de toda a sua produção para o resto do mundo.

O Estado cria órgãos reguladores, para o controle e regulação das atividades essenciais ao bem comum, estas agências são dotadas de mecanismos jurídicos capazes de coercitivamente determinar diretrizes que devam ser empregadas na prestação dos serviços delegados a particulares.

A privatização dos portos só será possível com a criação, pelo estado, de formas de controle e regulação eficientes. As agências reguladoras seriam uma forma de controle, mais especificamente a Agência Nacional de Transportes Aquaviários - ANTAQ responsável pela regulação das instalações portuárias, e fomentadora do desenvolvimento das atividades portuárias e do transporte aquaviário. 


\section{SOBERANIA}

Segundo Reale (2000, p.139), discorrendo sobre soberania:

Soberania é tanto a força ou o sistema de forças que decide do destino dos povos, que dá nascimento ao Estado Moderno e preside ao seu desenvolvimento, quanto a expressão jurídica dessa força no Estado constituído segundo os imperativos étnicos, econômicos, religiosos etc., da comunidade nacional, mas não é nenhum desses elementos separadamente: a soberania é sempre sócio-jurídico-política, ou não é soberania. É esta necessidade de considerar concomitantemente os elementos da soberania que nos permite distingui-la como uma forma de poder peculiar do Estado Moderno.

Para o autor, soberania não poderia ser definida exclusivamente através de uma concepção jurídica nem por uma concepção unicamente social, soberania seria um problema sócio-jurídico-politico.

Traz Reale (2000, p.140) o seguinte conceito operacional ${ }^{1}$ de soberania: "Soberania é o poder que tem uma Nação de organizar-se livremente e de fazer valer dentro de seu território a universalidade de suas decisões para a realização do bem comum."

Trata o autor da soberania como autonomia, autonomia para organizarse e gerir-se com o objetivo do bem comum. Nação seria uma sociedade organizada, constituída por um Estado independente, esta independência seria reflexo da soberania, da capacidade de auto determinar-se.

A Constituição Federal de 1988 contempla soberania sob variadas afirmações, como por exemplo, no art. $1^{02}$, que traz a soberania como fundamento do Estado Democrático de Direito; ainda traz no art. $14^{3}$ a soberania popular que deve ser exercida através do sufrágio universal e pelo voto direito e secreto; e o art. $170^{4}$, I, trata da soberania como princípio da ordem econômica.

\footnotetext{
1 "Quando nós estabelecemos ou propomos uma definição para uma palavra ou expressão, com o desejo de que tal definição seja aceita para os efeitos das idéias que expomos, estamos fixando um Conceito Operacional." (PASOLD, 2007, p.45).

${ }^{2}$ Constituição da República Federativa do Brasil de 1988: Art. 1. ${ }^{\circ}$ A República Federativa do Brasil, formada pela união indissolúvel dos Estados e Municípios e do distrito Federal, constitui-se em Estado Democrático de Direito e tem como fundamentos: I - a soberania;

${ }^{3}$ Constituição da República Federativa do Brasil de 1988: Art. 14. A soberania popular será exercida pelo sufrágio universal e pelo voto direto e secreto, com valor igual para todos, e, nos termos da lei, mediante: I - plebiscito; II - referendo; III - iniciativa popular.

${ }^{4}$ Constituição da República Federativa do Brasil de 1988: Art. 170. A ordem econômica, fundada na valorização do trabalho humano e na livre iniciativa, tem por fim assegurar a todos existência digna, conforme os ditames da justiça social, observados os seguintes princípios: I - soberania nacional.
} 
Segundo Leal (1999, p.22), trata soberania como conjunto autônomo de princípios jurídicos, regras e institutos sociais e políticos, reflete o autor:

Às vezes de modo polissêmico, a soberania é declarada pela norma jurídica como princípio ou fundamento necessariamente vinculado ao Estado, quando, a rigor, é ela, em si mesma, um conjunto autônomo de princípios jurídicos, de regras e institutos sociais e políticos justificadores do poder nacional.

Ainda segundo Leal (1999, p.37):

A personalidade jurídica internacional do Estado por reconhecimento de outros Estados não lhe transmite, de modo automático, o atributo da soberania entendida nos moldes de sua enunciação e conceituação moderna, porque o fato de um Estado ser sujeito de direito internacional, por si só, não legitima juridicamente a sua soberania, se esta não for exercida por delegação direita da vontade popular.

O autor traz a ideia que o simples fato de ser reconhecido por outras Nações não torna um pais dotado de soberania, a soberania emana do povo, ela partiria da vontade popular de ser independente, constituído uniformemente e com normativas universais dentro de seu espaço territorial.

Luigi Ferrajoli (2002), trata do tema soberania sob três formas; sendo o primeiro sob um prisma filosófico, uma construção de matriz jusnaturalista, que tem servido de base à concepção juspositivista do Estado; a segunda idéia trata soberania como potestas absoluta superiorem non recognoscens (poder supremo que não reconhece outro acima de si); por fim, trata da soberania sob o ponto de vista da teoria do direito, em que a soberania esta em contraste com o paradigma do estado de direito e da sujeição de qualquer poder à lei.

Segundo Ferrajoli:

Se o Estado é soberano internamente, ele o é por necessidade, não existindo fontes normativas a ele superiores, também externamente. Mas a sua soberania externa, juntando-se a soberania paritária externa dos outros Estados, equivale a uma soberania selvagem que reproduz, na comunidade internacional, o estado de natural desregramento, que internamente a sua própria instituição havia negado e superado. É assim que a criação do Estado soberano como fator de paz interna e de superação do bellum omnium (guerra de todos) entre as pessoas de carne e osso equivale a fundação simultânea de uma comunidade de Estados 
que, justamente por serem soberanos, transformam-se em fatores de guerra externa na sociedade artificial de Leviatãs com eles geradas. (FERRAJOLI, 2002, p.40).

Para o autor a soberania interna não permite a existência de fontes normativas a ela superiores, sendo assim, dela emana a capacidade da produção normativa. Contudo, no campo externo a soberania leva a um eterno conflito, pois os Estados não precisam se sujeitar uns aos outros, pois todos são soberanos e independentes, sendo assim, a soberania geraria uma guerra externa permanente, cada Estado tem a liberdade absoluta de fazer aquilo que julga mais oportuno aos seus interesses.

Segundo Furlan, sobre soberania:

O dogma da soberania foi concebido historicamente para justificar a superioridade de um poder, livre de qualquer sujeição. Tomava-se a soberania pelo mais alto poder, a supremitas, traço essencial para distinguir o Estado dos demais poderes que com ele disputavam. Do ponto de vista interno, porém, a soberania, como conceito jurídico e social, é bem mais aceita, em que pese ser da essência do ordenamento estatal uma superioridade e supremacia. (FURLAN, 2004, p.20).

Furlan (2004) também traz soberania como superioridade máxima de um poder, sem sujeição a nenhum outro, sem, portanto, limitações. Entretanto, Ferrajoli traz alguns fatores que servem para alterar, limitar a soberania interna e externa dos Estados, como por exemplo, a Declaração dos Direitos do Homem e do Cidadão, de 1789, as cartas constitucionais, que traz o princípio da legalidade, direitos fundamentais, tornando a relação entre Estado e cidadão uma relação entre dois sujeitos com direitos e obrigações.

A criação do Estado constitucional de direito vai de encontro a idéia de soberania como: potestas absoluta superiorem non recognoscens (poder supremo que não reconhece outro acima de si), pois o Estado constitucional garante direitos aos cidadãos que são protegidos e exercidos através da soberania, utilizando a soberania não como forma de único poder a ser exercido e cumprido, mas como meio para realizações sociais, a soberania advindo dos cidadãos que devem ser respeitados como sujeitos de direitos. 


\section{PORTOS PÚBLICOS E PRIVADOS SEGUNDOA LEI 8.630 DE 25 DE FEVEREIRO DE 1993}

As facilidades na procura e localização dos mais diversos produtos através da internet e dos meios de comunicação, além das necessidades humanas serem as mais diversas possíveis ocasionou um aumento das negociações mundiais, e conseqüente aumento do comércio mundial; um produto encontrado muitas vezes do outro lado do mundo, para chegar ao seu destinatário/comprador utiliza o transporte marítimo e conseqüentemente os portos para serem descarregados e entregues aos seus compradores/consumidores.

A indústria portuária presta serviços a estes consumidores na entrega das mercadorias, e deve este serviço ser de qualidade e ágil o suficiente para atender as expectativas dos seus usuários.

Segundo Porto, ao discorrer sobre portos públicos ou privados:

Em 1923, MacElwee afirmava que o importante não era de quem era o porto ou por quem era gerenciado, mas a forma como ele, porto, era administrado, devendo sê-lo de modo mais eficiente e rentável possível. Atualmente, o que se cobra de ambos (setor público ou privado) é a eficiência e qualidade, uma vez que alguém (usuário) está pagando por um serviço e quer um tratamento adequado, principalmente preços de mercado concorrencial. (PORTO, 1999, p.218).

Porto escreve sob uma visão basicamente capitalista, por meio de um prisma econômico do melhor serviço pelo menor preço possível; sob esta idéia que foi gerado o modelo de privatizações no Brasil, podendo ser acrescentado mais um fator importante, a massificação, ou melhor distribuição dos produtos/ serviços privatizados.

A atividade econômica é reservada preferencialmente a particulares, que a desempenham como derivação do princípio da propriedade privada.

Os serviços públicos são de titularidade do Estado, sob o regime do Direito Público, sendo obedecidos princípios como: continuidade, igualdade e mutabilidade.

O desenvolvimento de um modelo regulatório de Estado acarretou ampliação da disciplina estatal sobre a atividade privada, e possibilitou a fiscalização/regulação das atividades delegadas a particulares que antes eram de responsabilidade estatal. 
O endividamento econômico do Estado brasileiro conduziu a uma crise, caracterizada pela ausência de recursos para desempenho das funções estatais essenciais, os serviços públicos na área da educação, saúde, previdência e assistência social foram reduzidas a ineficiência, sendo algumas destas atividades exercidas por particulares sob o regime das privatizações.

A viabilidade deste modelo depende da existência de uma competência regulatória. Se o Estado reduzir sua atuação direta e atribuir aos particulares o poder de levar avante inúmeras atividades, a contrapartida será a regulação.

As atividades privadas relacionadas com a satisfação de interesse público não podem ser tratadas como se envolvessem apenas uma questão de interesse econômico dos particulares. Surge um conceito intermediário entre serviço público e atividade econômica em sentido estrito. São atividades que apresentam características peculiares a ambos os conceitos e cujo regime jurídico não é integral ou exclusivamente de Direito público ou de Direito privado.

O regime jurídico aplicável passa a ser o do Direito Privado, mas subordinado ao Direito Público e fortemente impregnado por princípios restritivos da autonomia privada.

Esse campo de atividades pressupõe uma intervenção regulatória extremamente significativa e intensa. O Estado desempenha competências regulatórias relevantes não apenas sobre os serviços públicos propriamente ditos, mas também sobre este outro campo intermediário, em que as atividades são prestadas por particulares sob regime jurídico mais severo.

Incidem os princípios da proporcionalidade e da subsidiariedade, no sentido de ser mais adequado retirar a atividade do âmbito do regime do Direito público como forma de promover a realização de interesses fundamentais.

Não significa, portanto, o desaparecimento do instituto do serviço público. Somente pode ser submetidas ao regime intermediário algumas atividades, aquelas que possam ser desempenhadas mais adequadamente e sem risco de comprometimento do serviço. Existem setores que exigem a manutenção do regime de Direito público.

Ainda segundo Porto, ao fazer referência ao padrão de tecnologia operacional da atividade portuária:

Assim, os portos brasileiros, na virada do século, terão duas tarefas básicas: perseguir o padrão de tecnologia operacional da atividade (inclusive infra- 
estrutura), em consonância com o transporte marítimo; e modelar suas estruturas organizacionais para o atendimento a uma atividade cada vez mais comercial e competitiva, sob a égide do consumidor. (PORTO, 1999, p.218).

O autor discute uma reestruturação, reaparelhando os portos brasileiros visando a modernização e conseqüente melhoramento na prestação dos serviços, beneficiando os utilizadores destes serviços.

Porto ainda traz a "reengenharia" dos portos:

Essa "reengenharia" portuária obrigou a atividade, mais especificamente as administrações portuárias, a assumir funções não estritamente portuárias como também comerciais, industriais e de distribuição física de mercadorias, agregando valor a atividade, criando, assim, os chamados portos de segunda e terceira geração. Como resultante de todos este processo, a atividade portuária passou a ser intensivamente dependente de capital, de elevado consumo de meio ambiente e menos dependente da utilização de mão-deobra.(PORTO, 1999, p.222).

Estas modernizações muitas vezes esbarram na falta de capacidade econômica dos Estados, que para não deixar a sociedade sem o serviço opta por transferi-lo para a atividade privada.

A Lei 8.630/1993, denominada Lei dos Portos, segundo Márcio Righetti (2008) "verdadeira espinha dorsal do direito portuário", propõe mudanças necessárias nos portos com o intuito de modernizar e melhorar o funcionamento dos terminais portuários, e conseqüentemente desenvolver este setor com qualidade.

Segundo Pasold, que escreve sobre a estrutura capitular da lei 8.630/93:

O segundo capítulo cuida "Das Instalações Portuárias" e abrange do artigo $4 \mathrm{o}$ ao $6 \mathrm{o}$, atualmente. No projeto original o capítulo estendia-se até o artigo 7 , mas este foi vetado. (PASOLD, 2007, p.49).

$\mathrm{O}$ artigo $40^{5}$, da Lei 8.630/93, trata das instalações portuárias, e o direito ao interessado de construir, reformar, ampliar, melhorar, arrendar e explorar instalações portuárias.

${ }^{5}$ Art. $4^{0}$ : Das instalações Portuárias:

Fica assegurado ao interessado o direito de construir, reformar, ampliar, melhorar, arrendar e explorar instalação portuária, dependendo: 
Em consonância com a distinção constitucional entre serviço público (art. 175 da CF/88) e atividade econômica em sentido estrito (art.173 da CF/88), e ainda em conformidade com os princípios da livre concorrência (arts. $1^{\circ}$, IV, e 170, IV da CF/88), o art. $4^{\circ}$ da Lei $n^{\circ}$ 8.630/93, Lei dos Portos, estabeleceu duas modalidades de exploração de instalações portuárias por parte de empresas privadas.

Por um lado, aludiu a terminais de uso público, destinados à prestação de serviços públicos portuários, dirigidos aos potenciais usuários em geral e com as garantias de direito público. Por outro previu terminais de uso privativo misto, destinados à movimentação e armazenagem de carga própria do titular do terminal, e, excepcionalmente, a movimentação de carga de terceiros.

Como terminal de uso público entende-se aquele que se destina a prestação dos serviços portuários previstos no art. 21 , da $\mathrm{CF} / 88$. A exploração dos terminais de uso público, nos termos do art. 13, I, e art. 14, I, "a" e parágrafo único da Lei $\mathrm{n}^{\mathrm{o}} 10.233 / 01$, que dispõe sobre a reestruturação dos transportes aquaviários e cria a ANTAQ, é outorgada por meio de contrato de concessão. ${ }^{6}$

Os terminais privativos foram criados para que as grandes empresas, os grandes usuários de serviços de transporte marítimo pudessem adotar uma solução própria, legítima, de natureza privada, para a movimentação expressiva de carga própria.

A criação de terminal portuário de uso privativo é objeto de mera autorização, nos termos do art. 13, V, e art. 14, III, "c", da Lei n 10.233/01, regulamentados pela Resolução n 517/05 da ANTAQ ${ }^{7}$.

I - de contrato de arrendamento, celebrado com a União no caso de exploração direta, ou com sua concessionária, sempre através de licitação, quando localizada dentro dos limites da área do porto organizado;

II - de autorização do ministério competente, quando se tratar de terminal de uso privativo, desde que fora da área do porto organizado, ou quando o interessado for titular do domínio útil do terreno, mesmo que situado dentro da área do porto organizado.

$\S 1^{\circ}$ A celebração do contrato e a autorização a que se referem os incisos I e II deste artigo devem ser precedidas de consulta à autoridade aduaneira e ao poder público municipal e de aprovação do Relatório de Impacto sobre o Meio Ambiente.

$\S 2^{\circ}$ A exploração da instalação portuária de que trata este artigo far-se-á sob uma das seguintes modalidades:

I - uso público;

II - uso privativo.

${ }^{6}$ BRASIL. Lei $\mathbf{n}^{\mathbf{0}} \mathbf{1 0 . 2 3 3}$, de 05 de junho de 2001. Dispõe sobre a reestruturação dos transportes aquaviário e terrestre, cria o Conselho Nacional de Integração de Políticas de Transporte, a Agência Nacional de Transportes Terrestres, a Agência Nacional de Transportes Aquaviários e o Departamento Nacional de Infra-Estrutura de Transportes, e dá outras providências. Disponível em: http:// www.planalto.gov.br/ccivil_03/Leis/LEIS_2001/L10233.htm. Acesso em: 20 jun. 2008.

${ }^{7}$ ANTAQ - Agência Nacional de Transportes Aquaviários. 


\section{A PRIVATIZAÇÃO DOS PORTOS NA GRÃ-BRETANHA E NA CHINA}

$\mathrm{O}$ aumento do envolvimento do setor privado nos portos tem sido justificado principalmente por princípios mercadológicos baseados no lucro. Uma das motivações é erradicar deficiências portuárias, diminuindo a quantidade de trabalhadores portuários pela tecnologia. Ainda justificam a entrada do setor privado pelo aporte financeiro, haja vista, a construção de novas instalações portuárias necessitarem de elevados investimentos financeiros, que não poderiam ser custeados pelo setor público sem a ajuda do privado.

Ainda serve como justificativa a concorrência entre portos, o que causaria a diminuição dos preços e maior lucratividade para armadores, empresas que utilizam os portos, e os consumidores em geral, com o repasse aos produtos finais.

Justificando a privatização dos portos esta a questão da burocracia. Empresas privadas tomam suas decisões mais rapidamente, podendo acompanhar as necessidades e mudanças sociais com agilidade e eficiência, diferentemente do setor público que devido a burocracia e muitas vezes incompetência de seus funcionários demora a tomar decisões, prejudicando o serviço e não atendendo as necessidades dos usuários.

A privatização dos portos britânicos foi baseada, segundo o autor Baird, nos seguintes objetivos:

A política de privatizações da indústria portuária britânica foi baseada em cinco objetivos principais, a maior parte deles também relevantes na venda de outros bens do estado. Esses objetivos foram: Melhorar a administração; Aumentar a eficiência; Gerar receita para o governo; Encorajar a propriedade partilhada; Reduzir o poder dos sindicatos. (BAIRD, 1999, p.174).

Segundo Baird (1999, p.181), discorrendo sobre o programa de privatização dos portos britânico: "Os 19 portos estatais antigamente operados pelo Conselho Britânico de Transportes e Docas (BTDB) foram transferidos para o setor privado em 1983, quando as ações foram vendidas ao público e a investidores de instituições". Continua o autor: 
Como esses eram portos antigos, vários tinham grandes extensões de terra, o que não é mais um requisito para o comércio marítimo. As áreas terrestres dos portos perto do centro da cidade representavam uma oportunidade de investimento particularmente atraente, com a perspectiva de se criarem novas lojas, espaços de lazer, negócios e residências ao longo da extensa zona portuária. Enquanto a Companhia e seus acionistas se beneficiaram com a aquisição de portos a baixo custo, o preço mais alto das propriedades da zona portuária veio a aumentar os lucros.(BAIRD, 1999, p.182).

Já na China, os portos eram vistos como empecilhos ao crescimento, gargalos na expansão crescente da economia. Os portos eram obsoletos, tanto em estrutura, quanto em serviços. Esta deficiência no escoamento das exportações e importações causava grandes prejuízos ao país.

Segundo Oliveira, escrevendo sobre a situação crítica dos portos chineses, revela o autor:

Percebeu o governo chinês que era impraticável manter em alta o desenvolvimento do país, amparado basicamente pelo comércio com o exterior, tendo portos obsoletos, não só quanto aos equipamentos, mas também com relação à própria estrutura de serviços. Não acompanhando, nem de longe, a esfuziante expansão da economia, passaram os portos chineses a represar as exportações e importações, causando inestimáveis prejuízos. (OLIVEIRA, 2004,p.119).

Essa necessidade de investimentos e modernização no setor portuário, levou o governo chinês, por falta de recursos próprios, obter capitais externos para as obras e reequipamentos necessários ao setor.

De acordo com Oliveira:

Para solução do clássico problema da falta de recursos destinados à modernização do setor, o governo lançou mão dos capitais externos para as obras e reequipamentos necessários. Não são apenas empréstimos e financiamentos oficiais, mas também pesados investimentos privados, particularmente de empresas japonesas e americanas. Alguns terminais particulares pertencentes a multinacionais que produzem no país já estão em operação e outros em fase de estruturação. (OLIVEIRA, 2004, p.120).

Traz o autor Oliveira (2004, p.122), como exemplo de eficiência o porto de Hong Kong: “A exemplo de Nova York, Roterdã, Hamburgo, Cingapura, 
entre outras, a trepidante cidade de Hong Kong nasceu e prosperou em volta do grande porto, um dos mais privatizados do planeta."

Ainda fazendo referência a privatização dos portos chineses, encerra:

Seguindo a abertura para a economia de mercado - mais firme sob o comando de $\mathrm{Zhu}$ - os portos estão sendo privatizados. Em Xangai, entre outros, dois grandes terminais privados, arrendados por 50 anos, aos grupos Hutchison e PeONedloyd, com modernas instalações, já dominam a movimentação de contêineres. (OLIVEIRA, 2004, p.123).

A China, além de desenvolver os seus portos; a indústria naval também passou a contar com aportes financeiros estrangeiros, atraídos pela mãode-obra barata e excesso de matérias primas. Ainda na área da indústria naval, a China tornou-se um dos maiores fabricantes e exportadores de contêineres. Importante referir a presença da China no transporte marítimo, com uma frota mercante que chega a cerca de $10 \%$ da frota mundial.

Esta transferência das atividades portuárias para a iniciativa privada necessita de regulação estatal, podendo ser feita por agências reguladoras.

\section{AGÊNCIAS REGULADORAS: ANTAQ}

O Estado não conseguindo atender aos anseios sociais e desenvolver a prestação dos serviços públicos a contento, passou, para a iniciativa privada, algumas atividades. Ao tornar responsável a iniciativa privada, o Estado criou mecanismos de controle e regulação das atividades essenciais, para evitar um colapso social ou uma deficiência na prestação dos serviços antes estatais.

Para o controle e regulação dessas atividades essenciais o Estado criou agências reguladoras, dotadas de mecanismos jurídicos capazes de coercitivamente determinar diretrizes que devam ser empregadas na prestação destes serviços.

Segundo Justen Filho (2005, p.464), discorrendo sobre as agências reguladoras independentes: “A adoção de um modelo regulatório de Estado conduz a fragmentação das competências normativas e decisórias estatais. Surgem entidades administrativas encarregadas da gestão setorial”. 
O autor (JUSTEN FILHO, 2005, p.466) traz um conceito operacional ${ }^{8}$ para agência reguladora independente: "Agência reguladora independente é uma autarquia especial, sujeita a regime jurídico que assegure sua autonomia em face da Administração direta e investida de competência para a regulação setorial."

Justen Filho (2005) elenca alguns requisitos indispensáveis para caracterização de uma agência reguladora independente, e conseqüentemente pode-se concluir que quanto mais competente no âmbito regulatório for a agência, melhor serão os serviços regulados.

De acordo com Faria, trazendo um conceito de agência reguladora:

Trata-se de entidade de direito público, criada por lei específica, destinada a regular a prestação de determinado serviço público e a fiscalizar as delegatárias da prestação dos mesmos, com vistas a obtenção, pelos usuários, do serviço adequado, continuado e em condições módicas, além de estabelecer metas a serem cumpridas no tempo e no espaço.(FARIA, 2007, p.62).

Exemplo de agência reguladora é a Agência Nacional de Transportes Aquaviários - ANTAQ - criada pela Lei n. 10.233, de 05.06.2001. Esta autarquia tem por objeto a formulação, controle e fiscalização da política de transportes aquaviários e das instalações portuárias. Entre as atribuições que lhes é conferida, a delegação da prestação de serviços mediante contrato de concessão e contrato de permissão. Em ambos os casos, os delegatários devem ser escolhidos mediante certame licitatório.

A Agência Nacional dos Transportes Aquaviários - ANTAQ:

A Agência Nacional de Transportes Aquaviários - ANTAQ, criada pela Lei $\mathrm{n}^{\circ}$ 10.233, de 5 de junho de 2001, é entidade integrante da Administração Federal indireta, submetida ao regime autárquico especial, com personalidade jurídica de direito público, independência administrativa, autonomia financeira e funcional, mandato fixo de seus dirigentes, vinculada ao Ministério dos Transportes, com sede e foro no Distrito Federal, podendo instalar unidades administrativas regionais. Tem por finalidades: I - implementar, em sua esfera de atuação, as políticas formuladas pelo Ministério dos Transportes e pelo

\footnotetext{
8 "Quando nós estabelecemos ou propomos uma definição para uma palavra ou expressão, com o desejo de que tal definição seja aceita para os efeitos das idéias que expomos, estamos fixando um Conceito Operacional." (PASOLD, 2007, p.45).
} 
Conselho Nacional de Integração de Políticas de Transporte-CONIT, segundo os princípios e diretrizes estabelecidos na Lei $n^{\circ} 10.233$, de 2001; e II - regular, supervisionar e fiscalizar as atividades de prestação de serviços de transporte aquaviário e de exploração da infra-estrutura portuária e aquaviária, exercida por terceiros, com vistas a: a) garantir a movimentação de pessoas e bens, em cumprimento a padrões de eficiência, segurança, conforto, regularidade, pontualidade e modicidade nos fretes e tarifas; b) harmonizar os interesses dos usuários com os das empresas concessionárias, permissionárias, autorizadas e arrendatárias, e de entidades delegadas, preservando o interesse público; e c) arbitrar conflitos de interesse e impedir situações que configurem competição imperfeita ou infração contra a ordem econômica. (ANTAQ, 2007).

Sendo assim, terminais portuários privados, devem ser regulados/ fiscalizados pela ANTAQ, porém esta não é a única faceta da Agência, devendo ser também fomentadora do desenvolvimento das atividades portuárias e do transporte aquaviário.

O Decreto n. 4.122, de 13 de fevereiro de 2002, aprovou o Regulamento da Agência Nacional de Transportes Aquaviários - ANTAQ. No art. 30 do Regulamento, estão elencadas as competências da agência, com o objetivo de atender os interesses públicos e o desenvolvimento da atividade regulada, notase a grande carga regulatória que consta neste artigo, dando inúmeros poderes a ANTAQ quanto a regulação/fiscalização do setor.

\section{CONCLUSÃO}

A privatização de terminais portuários não afeta a soberania, pois a solução para um possível abalo a este elemento constitutivo do Estado esta na possibilidade que tem o ente estatal de criação normativa ser de competência única e exclusiva sua.

A criação normativa possibilita ao Estado a instituição de agencias reguladoras capazes de controlar e fiscalizar o setor entregue para exploração de particulares, utilizando mecanismos que permitem até mesmo a retomada da prestação do serviço pelo Estado.

Sendo assim a própria soberania é a resposta para a perda da soberania devido à privatização dos terminais portuários, pois ela permite a delegação sem perda de controle. 


\section{REFERÊNCIAS}

BAIRD, Alfred J. Cidades e Portos: os espaços da globalização. Organizadores: Geraldo Silva e Giuseppe Cocco. Rio de Janeiro: DP\&A, 1999.

BRASIL. Lei $\mathbf{n}^{\mathbf{0}} \mathbf{1 0 . 2 3 3}$, de 05 de junho de 2001. Dispõe sobre a reestruturação dos transportes aquaviário e terrestre, cria o Conselho Nacional de Integração de Políticas de Transporte, a Agência Nacional de Transportes Terrestres, a Agência Nacional de Transportes Aquaviários e o Departamento Nacional de Infra-Estrutura de Transportes, e dá outras providências. Disponível em: http://www.planalto.gov.br/ccivil_03/Leis/ LEIS_2001/L10233.htm. Acesso em: 20 jun. 2008.

. Agência Nacional de Transportes Aquaviário - ANTAQ. Disponível em: http://www.antaq.gov.br/Portal/antaq.asp. Acesso em: 03 jul. 2007.

FARIA, Edimur Ferreira de. Curso de Direito Administrativo Positivo. Belo Horizonte: Del Rey, 2007

FERRAJOLI, Luigi. A soberania no mundo moderno. São Paulo: Livraria Martins Fontes Editora Ltda, 2002.

FURLAN, Fernando de Magalhães. Integração e soberania. O Brasil e o Mercosul. São Paulo: Aduaneiras, 2004.

JUSTEN FILHO, Marçal. Curso de Direito Administrativo. São Paulo: Saraiva, 2005.

LEAL, Rosemiro Pereira. Soberania e Mercado Mundial. São Paulo: Editora de Direito LTDA, 1999.

OLIVEIRA, Carlos Tavares de. China o que é preciso saber. São Paulo: Aduaneiras, 2004.

PASOLD, Cesar Luiz. Prática da Pesquisa Jurídica e Metodologia da Pesquisa Jurídica. Florianópolis: Editora OAB/SC, 2007. 
PORTO, Marcos Maia. Cidades e Portos: os espaços da globalização. Organizadores: Geraldo Silva e Giuseppe Cocco. Rio de Janeiro: DP\&A, 1999.

REALE, Miguel. Teoria do Direito e do Estado. São Paulo: Saraiva, 2000.

Recebido em: 2011-03-15 Aprovado para publicação em: 2012-09-13

Como citar: DE OLIVEIRA, Alvaro Borges; DANI, Felipe André. Soberania nacional e privatização dos terminais portuários. Scientia Iuris, Londrina, v.16, n.1, p.179-194, jul.2012. DOI: 10.5433/2178-8189.2012v16n1p179. 